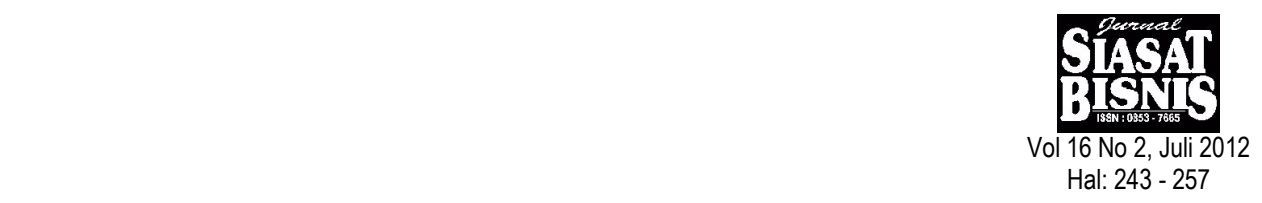

\title{
PENGGUNAAN LEVERAGE PADA PERUSAHAAN: PERBEDAAN ANTARA CEO PRIA DAN WANITA
}

\author{
Farida Titik Kritanti \\ Institut Manajemen Telkom \\ e-mail: farida_titik@yahoo.com
}

\begin{abstract}
Various studies show that women are more risk averse in making decisions and better long-term oriented. Women would rather risk averse than men, making it less likely they will use debt in their capital structure, since by increasing debt increases the risk of the company's financial means. This study want to test whether gender became a significant factor in financial leverage, to see whether there are differences in policy between the company's leverage, led by men and women. Financial leverage is used as a measure of corporate risk because these variables can be changed by the CEO. Data from companies listed on the Jakarta Stock Exchange as sample. The results showed that there were differences in leverage between firms that have a men CEO with the women CEO of a company. Men CEO use more debt than the women CEO. But for the performance measured by ROI, obtained different results for the type of industry studied. For the consumer goods industry, there are performance differences between the men CEO and the women. But for the internet service industry and enamel kitchen showedho performance difference between women $C E O$ with men CEO.
\end{abstract}

Key words: leverage, woman CEO, man CEO, performance

\begin{abstract}
Abstrak
Berbagai penelitian menunjukkan bahwa wanita lebih risk averse dalam mengambil keputusan dan lebih berorientasi jangka panjang. Wanita lebih suka menolak risiko dibandingkan pria, sehingga kecil kemungkinan mereka akan menggunakan hutang dalam struktur modalnya, karena dengan menambah hutang berarti memperbesar risiko keuangan perusahaan. Penelitian ini ingin menguji apakah jender menjadi faktor yang cukup signifikan dalam financial leverage, dengan melihat apakah ada perbedaan dalam kebijakan leverage antara perusahaan yang dipimpin oleh pria dan wanita. Financial leverage dipakai sebagai ukuran risiko perusahaan karena variabel ini bisa diubah oleh CEO. Sampel menggunakan data dari perusahaan yang listed di Jakarta Stock Exchange. Hasil penelitian menunjukkan bahwa ada perbedaan leverage antara perusahaan yang memilki CEO pria dan perusahaan dengan CEO wanita. CEO Pria menggunakan rata-rata hutang lebih banyak dibandingkan dengan CEO wanita. Namun untuk kinerja yang diukur dengan ROI, diperoleh hasil yang berbeda untuk jenis industri yang diteliti. Untuk industri consumer goods, ada perbedaan kinerja antara CEO wanita dan CEO Pria. Namun untuk industri internet service dan enamel kitchen menunjukan tidak ada perbedaan kinerja antara CEO wanita dengan CEO Pria.
\end{abstract}

Kata kunci: leverage, CEO wanita, CEO pria, kinerja

\section{PENDAHULUAN}

Bukan hal yang biasanya bahwa jumlah pengusaha wanita terus meningkat secara meyakinkan di dunia. Valencia (2006) melaporkan bahwa kira-kira 40,54\% dari 73 juta orang yang aktif dalam dunia usaha di 34 negara adalah wanita. Sitterly's (2001) menemukan bahwa 40-50\% dari semua bisnis dimiliki oleh wanita, dengan tingkat kesuksesan $75 \%$. Di wilayah asia timur $18-30 \%$ wanita yang bekerja di Indonesia, Malaysia, Philipina, Singapura dan Thailand adalah wanita.

Penelitian ini akan melakukan pembahasan lebih lanjut tentang paradigma principat agent dengan melakukan investigasi dimensi lain dari agency problem, yaitu me- 
ngenai pengaruh dari diversitas diantara top manajer dalam preferensi risiko mereka. Pengambilan risiko akan dipengaruhi oleh jender dari CEO atau diversitas jender dari dewan direksi atau top manajemen. Penelitian tentang jender yang akan mempengaruhi kinerja perusahaan menjadi hal penting dalam pembahasan ini.

Keanekaragaman jender dalam posisi top executive telah menjadi fokus perdebatan pada beberapa dekade terakhir ini. Banyak literatur yang menyatakan bahwa ada "glass ceiling" dimana wanita tidak nampak dalam jajaran manajemen senior di perusahaan. Merujuk pada penelitian Smith (2005), telah terjadi peningkatan jumlah wanita yang berada dalam jajaran dewan direksi di perusahaan. Namun, menurut Marinova et al. (2004) posisi wanita yang mencapai posisi top executive masih sangat sedikit di sebagian besar Negara di dunia, kecuali di US dan beberapa Negara Eropa. Efek positif atas kinerja mengimplikasikan bahwa semakin banyaknya wanita di posisi top perusahaan atau dalam jajaran dewan direksi akan berhubungan erat dengan meningkatnya produktivitas dan profitabilitas perusahaan. Berdasarkan pada Catalist (2004), yang meneliti top manajemen wanita di perusahaan yang berbeda menunjukkan bahwa mereka mencapai kondisi keuangan yang lebih baik.

Apakah pria dan wanita secara sistematik berbeda atas respons mereka terhadap risiko adalah sebuah pertanyaan yang secara ekonomi penting. Jika wanita lebih sensitif terhadap risiko dibanding pria, pasti hal ini akan terefleksikan dalam semua aspek dalam pengambilan keputusan mereka. Di sebuah penelitian yang membandingkan tendensi wanita dan pria dalam partisipasinya di berbagai aktivitas yang berisiko, Byrnes (1999) melaporkan bahwa pria cenderung berani mengambil risiko dibandingkan wanita yang konservatif.

Penelitian yang mempelajari risiko keuangan (financial risk) yang dilakukan oleh wanita telah banyak dilakukan. Jianakoplos and Bernasek (1996) mempelajari hubungan antara prosentase asset yang berisiko dengan total asset dan beberapa variabel lainnya termasuk jender dan kesejahteraan. Penelitian mereka menemukan bahwa wanita single relatif lebih risk averse dibanding pria atau orang yang berpasangan. Menurut penelitian Strelcova (2004), ditemukan bahwa return saham dari perusahaan yang baru dipimpin oleh wanita, lebih rendah secara signifikan dibanding return saham perusahaan yang dipimpin oleh pria. Namun penelitian ini tidak menemukan bukti bahwa ada perbedaan dalam leverage perusahaan antara perusahaan yang CEO-nya wanita dan CEO-nya pria.

Kebanyakan studi didasarkan pada data di Amerika serikat dan hamper sebagian besar studi tersebut dilakukan hanya pada perusahaan besar. Shrader et al. (1997) menganalisa 200 terbesar perusahaan di Amerika Serikat dan mereka tidak menemukan hubungan positif yang signifikan antara anggota dewan direksi wanita dan kinerja perusahaan (diukur dengan ROA dan ROE). Mereka bahkan menemukan hubungan negatif yang signifikan di beberapa kasus. Kochan et al. (2003) juga menemukan hubungan yang tidak positif antara jender diversity di dalam manajemen dan kinerja pada perusahaan-perusahaan di Amerika Serikat. Berbeda dengan penemuan tersebut, Catalyst (2004) dan Adler (2001) menemukan korelasi yang positif antara "female friendly" dengan kinerja perusahaan pada 500 Perusahaan di US Hanya sedikit studi yang dilakukan di luar US pada topik ini. Du Rietz and Henrekson (2000) menganalis kinerja perusahaan dan wanita dalam jajaran dewan direksi untuk perusahaan di Swedia menemukan bahwa perusahaan dengan wanita ada di dalam dewan direksi nampak underperform. Di Denmark, Rose (2004) tidak menemukan hubungan yang signifikan antara prosentase dalam dewan direksi dan kinerja perusahaan untuk perusahaan yang listed (diukur dengan Tobin's Q). Eckel and Grossman (2008) menyatakan telah dilakukan berbagai penelitian tentang hipotesis bahwa wanita dan pria merespon secara berbeda terhadap risiko, baik dilipandang dari sudut sosiologi maupun psikologi. Meskipun begitu perlu diberi catatan bahwa sikap terhadap risiko tersebut cenderung bervariasi tergantung pada lingkungannnya. Ini berarti kesimpulan dari studi-studi terdahulu masih ambigiu.

Penelitian penelitian terdahulu di Negara lain yang menunjukkan hasil yang berbeda itulah yang menimbulkan ketertarikan untuk bisa menjawab pertanyaan apakah CEO wanita dan CEO pria mempunyai sikap yang 
berbeda dalam financial risk. Hal ini didasarkan penemuan penelitian terdahulu bahwa ada perbedaan dalam risk tolerance antara wanita dan pria. Sebagai ukuran dalam penelitian ini akan digunakan rasio leverage yang merupakan perbandingan antara hutang jangka panjang dengan total asset, dimana data tersebut sudah tersaji dalam Indonesian Capital Market Directory (ICMD) terbitan Jakarta Stock Exchange (JSX). Kemudian pertanyaan selanjutnya adalah, apakah kinerja CEO wanita berbeda dengan CEO pria dalam suatu perusahaan. Strelcova (2004) menyebutkan ada beberapa ukuran yang bisa digunakan untuk mengukur kinerja, seperti Return on Equity, Retun on Investemnt, Stock kinerja, dan lainlain dalam penelitian ini Return on Investment dipilih sebagai ukuran kinerja perusahaan. Oleh karena itu, tujuan penelitian ini adalah: (1) Untuk menguji apakah ada perbedaan penggunaan leverage antara perusahaan dengan CEO wanita dan perusahaan dengan CEO pria dan (2) Untuk menguji apakah ada perbedaan kinerja antara perusahaan dengan CEO wanita dan perusahaan dengan CEO pria.

\section{KAJIAN PUSTAKA}

Sudarsanam (2007) menyatakan bahwa studi mengenai efek jender terhadap performance perusahaan adalah hal yang penting. Meskipun begitu, sangat sedikit penelitian yang menilai tentang pengaruh jender atas pengambilan risiko perusahaan dan akibatnya, terhadap kinerja perusahaan walaupun studi psikologis mengindikasikan bahwa pria dan wanita berbeda dalam preferensi risiko mereka.

\section{Risk Preferences}

Gitman (2009) menyatakan bahwa nilai rasa atas risiko akan berbeda-beda diantara para manajer atau diantara perusahaan. Karena itu penting untuk menguraikan tingkat risiko yang secara umum diterima. Ada tiga (3) preferensi risiko yaitu, risk averse, risk indifferent, dan risk seeking, seperti terlihat pada gambar 1. a) Risk-indifferent manager, the required return does not change as riskgoes from $x_{1}$ to $x_{2}$. b) Risk-Averse manager, the required return increases for an increase in risk. Because they shy away from risk, these manager require higher expected returns to compensate them for taking greater risk. c) Risk - seeking manager, the required return decreases for an increase in risk.

Hampir sebagian besar manager adalah risk averse, ketika risiko naik maka menghendaki peningkatan dalam return. Mereka umumnya cenderung conservative ketika menghadapi risiko untuk perusahaan yang mereka jalankan.

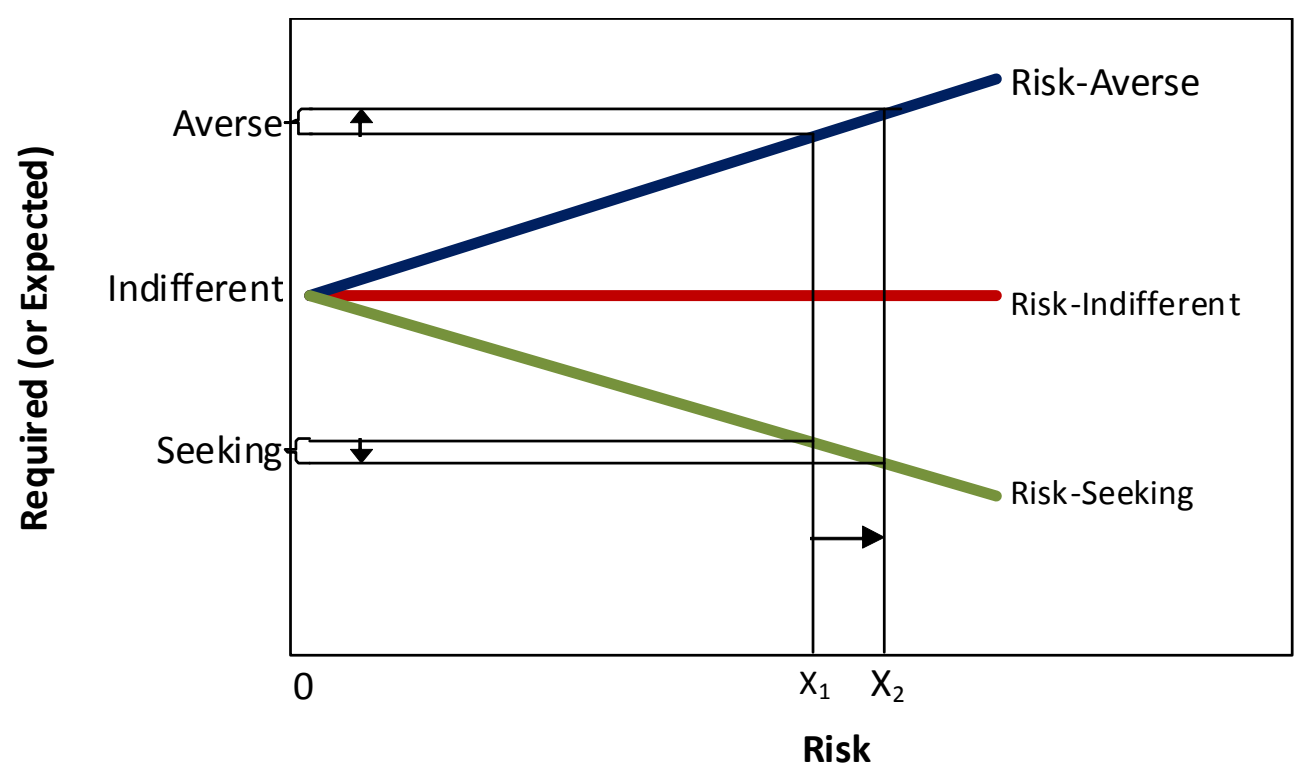

Sumber: Gitman, (2009), Principal of managerial Finance.

Gambar 1. Risk Preference behavior 
Eckel and Grosmman (2008) menemukan dalam penelitiannnya, women are more risk averse than men. Gupta et al. (2009), in the business world women are still viewed as risk averse. Peneltian yang lain tentang risiko financial oleh wanita juga telah dipelajari, beberapa peneliti seperti Bajtelsmith and VanDerhei (1996) dan Hinz, McCharty, dan Turner (1996) telah menemukan bahwa wanita menginvestasikan uang pensiun mereka secara lebih konservatif dibandingkan pria. Jianakoplos and Bernasek (1996) mempelajari tentang hubungan antara prosentase dari asset yang berisiko terhadap total asset dengan variabel seperti jender dan kesejahteraan. Studi mereka menunjukkan bahwa wanita single relative lebih risk averse dibanding pria atau pasangan yang menikah. Studinya juga membandingkan antara risiko yang bisa mereka terima diantara beberapa kelompok yang berbeda dan hasilnya menunjukkan bahwa wanita menerima diri mereka sendiri sebagai sosok yang risk averse.

Bagaimana wanita dan pria berbeda dalam respon mereka terhadap pilihan yang berisiko ditentukan oleh lingkungannya, apakah lebih didominasi pria atau lebih didominasi pria. Booth and Noolen (2009) dalam penelitiannya menunjukkan bahwa female riskaversion was higher among girls from co-ed schools relative to girls from single-sex schools. Sudarsanam dan Huang (2005) dalam penelitiannnya atas 2527 sampel di US, menunjukkan bahwa kehadiran wanita CEO berhubungan dengan meningkatnya acquisition-related risk. Sedangkan kinerja yang berhubungan dengan akuisisi, mereka menemukan bahwa pasar merespon lebih menyenangkan atas $M$ \& A yang dibuat oleh CEO wanita dibandingan yang dibuat CEO pria. Charness and Gneezy (2004) melaporkan bahwa wanita menginvestasikan lebih sedikit dan nampaknya lebih risk averse dibanding pria. Nieesen and Ruenzi (2006) menemukan bahwa wanita yang menjabat sebagai manajer keuangan, "take less risk and follow a less extreme investment style", yang sekali lagi menunjukkan bahwa wanita lebih risk averse.

Menggunakan survey data dari 649 manager keuangan di empat Negara, Beckmann and Menkhoff (2008) menemukan bahwa: women fund managers are more risk averse and shy away from competition in tournaments.
Dwyer et al. (2002) dengan sampel manajer keuangan professional, dan menggunakan hampir 2,000 data investor mutual fund menemukan bahwa: women take less risk than men in their mutual fund investments. Meskipun begitu, observasi tentang perbedaan jender dalam pengambilan risiko secara signifikan berkurang ketika investasi keuangan mereka diawasi. Hal yang sama ditunjukkan pada penelitian, Atkinson, Baird and Frye (2003), mereka menemukan bahwa manajer mutual fund, baik pria maupun wanita menampilkan pola yang sama dalam kinerja dan risiko.

\section{Leverage}

Dua pertanyaan yang utama dalam bisnis adalah: haruskah bisnis meningkatkan atau mengurangi jumlah unit produksi dan haruskah perusahaan menggunakan hutang dalam jumlah banyak atau sedikit. Jawabannya tergantung pada bagaimana perubahan tersebut akan mempengaruhi risiko dan return.

Merujuk pada Gitman (2009), leverage digunakan perusahaan untuk menjelaskan kemampuan perusahaan menggunakan dana untuk menguatkan return bagi pemilik perusahaan (tercermin dalam Earning per share). Leverage ada ketika perusahaan memiliki beban tetap. Financial leverage adalah teknik penggunaan dana dari hutang atau saham preferen yang menimbulkan beban tetap, dalam rangka meningkatkan return on equity investment. Menurut Keown et al. (2005), Financial risk refers to the added variability in earning available to a firm's shareholders and the added chance of insolvency caused by the use securities bearing a fixed rate of return in the firms'capital structure. Firms that use higher levels of financial leverage also experienced higher volatility in earnings available to the commonstockholders. This higher volatility leads investor to require higher rates of return.

Jelena (2004) menggunakan perbandingan hutang jangka panjang dengan total aktiva sebagai ukuran Rasio leverage. Struktur modal perusahaan secara langsung mempengaruhi risiko finansialnya (financial risk), yaitu risiko perusahaan untuk bisa menutup kewajiban keuangannnya. Merujuk pada Gitman (2009) The more fixed-cost financing debt(including financial leases) and preffered 
stock- a firm has in its capital structure, the greater its financial leverage and risk. Financial risk depends on the capital structure decision made by the management, and the decision is affected by the business risk the firm faces.

Penelitian Strelcova (2004) atas 58 perusahaan yang dipimpin oleh CEO wanita selama 20 tahun menemukan bahwa tidak ada perbedaan leverage antara perusahaan dengan CEO wanita dan perusahaan dengan CEO pria.

\section{Kinerja}

Gitman (2009) dalam bukunya Principles of Managerial Finance, menyatakan bahwa Return On Assets (ROA) sering disebut juga Return On Investment (ROI), yang mengukur keefektifan manajemen dalam menghasilkan laba dengan asset yang tersedia. ROA yang tinggi lebih baik bagi perusahaan, ROA atau ROI dihitung dengan membagi pendapatan yang tersedia untuk pemegang saham biasa (earning available for common stockholder) dengan total aset

Dalam penelitiannnya atas perusahaan publik besar di US untuk berbagai industri, Erhardt et al. (2003) menemukan bahwa diversitas pada jajaran eksekutif perusahaan memiliki hubungan yang positif baik terhadap ROI maupun ROA. Korelasi yang positif ditemukan oleh Adler (2001) dan Catalyst (2004) yang mempelajari 500 perusahaan US Fortune, yang melihat hubungan antara prosentase wanita dalam jajaran dewan direksi dan value perusahaan. Sebuah studi Catalyst yang disponsori oleh Chubb corporation (2007) yang mendokumentasikan 500 perusahaan dengan lebih banyak wanita pada jajaran direksi memiliki kinerja (Return On Equity, Return on sales, dan return on invested capital) yang lebih baik. Efek positif yang signifikan juga ditemukan oleh Carter et al. (2003). Smith et al. (2006) dengan data panel dari 2.500 perusahaan terbesar di Danish menunjukkan bahwa share wanita diantara top eksekutif dan jajaran dewan direksi cenderung memiliki efek yang signifikan positif atas kinerja perusahaan. Penelitian ini juga menghasilkan bukti bahwa efek kinerja yang positif dihasilkan dari manajer wanita yang berpendidikan universitas, dan berhubungan dengan manajer wanita yang dipilih oleh stafnya. Bukti yang lain atas pengaruh posisi top manajemen dengan kinerja diberikan oleh Weber and Zulehner (2009). Hasilnya adalah ada asosiasi yang positif atas keberadaan minimal satu (1) wanita di dalam dewan direksi untuk 30.000 perusahaan di Austria. Sebagai tambahan studi terbaru dari Wilson and Altanlar (2009) di UK menunjukkan bahwa minimal ada satu (1) wanita dalam jajaran dewan direksi akan mengurangi risiko kebangkrutan

Sejalan dengan studi di US yang dominan positif, bukti penelitian di Eropa menunjukkan hasil yang bervariasi. Rose (2007) menggunakan sampel perusahaan yang listed di Copenhagen Stock Exchange selama 19982001, menemukan bukti bahwa wanita di jajaran dewan direksi tidak mempengaruhi kinerja perusahaan. Begitu juga dengan Francoeur et al. (2008), yang menggunakan data dari perusahaan-perusahaan di Kanada, menyimpulkan bahwa ternyata dengan memiliki lebih banyak wanita dalam jajaran direksi perusahaan atau dalam posisi top manajemen, tidak nampak menunjukan hasil return yang lebih besar secara signifikan. Randoy et al. (2006) menggunakan sampel perusahaan terbesar di Denmark, Norwegia dan Swedia menemukan bahwa tidak ada efek jender terhadap kinerja korporat. Bohran dan strom (2007) yang meneliti pada sampel perusahaan keuangan yang listed di Norwegia, menunjukkan hasil bahwa hanya satu (1) peneliti yang menemukan hubungan yang signifikan positif antara diversitas jender dalam dewan direksi dan kinerja perusahaan.

Dwyer et al. (2004) juga menemukan Efek negative atas diversitas jender ditunjukkan dalam situasi adhocracy culture, yang dikarakteristikan dengan orientasi eksternal, fokus pada diri sendiri dan persaingan. Dezso and Ross (2008) menemukan efek yang negative antara wanita CEO dengan kinerja perusahaan.

\section{METODE PENELITIAN}

Populasi dalam penelitian ini adalah semua perusahaan yang teedaftar di Bursa Efek Jakarta pada periode penelitian, yaitu 20012008. Indonesian Capital Market Directory yang diterbitkan Bursa Efek Jakarta digunakan untuk mencari sampel terpilih. Purposive sampling digunakan untuk mencari sampel dengan kriteria tertentu. 
Sampel yang dipilih adalah perusahaan yang memiliki CEO wanita dan perusahaan yang memiliki CEO pria selama periode yang diteliti, yaitu 2001 - 2008. Perusahaan tersebut juga harus memilki data lengkap yaitu data rasio Leverage dan ROI yang sudah ada dalam laporan keuangan perusahaan pada periode penelitian.

Data yang digunakan dalam penelitian ini adalah data sekunder yang dikumpulkan oleh pihak lain. Teknik yang digunakan adalah metode dokumentasi dari laporan keuangan yang bersumber dari Indonesian Capital Market Directory yang diterbitkan Bursa Efek Jakarta. Dari semua perusahaan yang terdaftar pada di Bursa Efek Jakarta pada periode penelitian, dipilih perusahaan yang pada tahun penelitian tersebut CEOnya adalah wanita, dengan melihat nama yang tertera pada laporan keuangan dalam ICMD. Hanya nama yang diyakini dimiliki oleh wanita yang akan dipilih menjadi sampel. Dari hasil penelusuran data diperoleh 3 perusahaan yang CEO-nya adalah wanita, lihat Tabel 1.

Setelah didapatkan perusahaan dengan CEO wanita pada periode penelitian, baru dicari perusahaan pembanding dari kelompok usaha yang sama, yaitu perusahaan yang pada tahun penelitian CEOnya adalah pria, yang kurang lebih memiliki kesamaan jenis usaha dengan perusahaan yang CEO-nya wanita. Hal ini dilakukan karena ada kemungkinan meskipun dalam industri yang sama tetapi memiliki jenis usaha yang berbeda. Selain itu perusahaan pembanding juga dicari yang kurang lebih memiliki modal yang tidak jauh berbeda, agar lebih fair dalam membandingkannya. Dari hasil penelusuran diperoleh perusahaan pembanding tersebut, yaitu seperti nampak pada Tabel 2.

Setelah didapat nama-nama perusahaan yang memiliki CEO wanita dan CEO pria, maka didapatkan data seluruh nilai rasio Leverage dan ROI (Return On Investment) dari perusahaan terpilih, selama tahun penelitian, seperti terlihat pada Tabel 3. Leverage ratio dipakai sebagai ukuran bagaimana seorang CEO dalam keputusan financial risk mereka yang didefinisikan sebagai perbandingan antara penggunaan hutang dengan total asset mereka. Sedangkan ROI (Return On Investment) digunakan sebagai ukuran kinerja CEO atas penggunaan seluruh dana mereka. Data rasio leverage dan ROI adalah data tahunan yang diambil dari ICMD yang diterbitkan oleh Bursa Efek Jakarta.

Setelah data leverage dan Return On Investment diperoleh maka kemudian akan dilakukan Uji beda atas perusahaan dengan CEO wanita dan perusahaan dengan CEO pria, yaitu dengan menggunakan T-Test. Ghozali (2001), Alat ini digunakan untuk menentukan apakah dua sampel yang tidak berhubungan memiliki niai rata-rata yang berbeda. Uji beda T-Test dilakukan dengan cara membandingkan perbedaan antara dua nilai rata-rata dengan standar error dari perbedaan rata-rata dua sampel. Dalam penelitian ini Independent Sample T-Test dipilih karena kelompok pria dan wanita berasal dari populasi yang berbeda.Untuk melihat homogenitas variance data antara CEO wanita dan CEO Pria, dilakukan uji Levene's Test. Level confidence pada penelitian ini adalah 95\% dengan level toleransi kesalahan 5\%. Kesimpulan hasil analisis pada penelitian ini diarahkan pada nilai-p (p-value). Bila nilai-p lebih besar dari batas toleransi 5\%, maka hasil analisis menerima hipotesisi null, berarti tidak ada perbedaan antara CEO Wanita dan CEO Pria. Tetapi bila nilai-p lebih kecil dari batas toleransi 5\%, maka hasil analisis menolak hipotesis null, yang berarti ada perbedaan antara CEO Wanita dan CEO Pria.

Tabel 1: Nama CEO Wanita, Perusahaan dan jenis usaha

\begin{tabular}{lll}
\hline Nama CEO & Nama Perusahaan & Kelompok usaha \\
\hline BRA Mooryati Soedibyo & Mustika Ratu & Consumer Good \\
Sylvia Efi Widyantari S & Dyviacom Others & Internet Service \\
Ir. Ratna setyakusuma & Kedaung Indah & Can Enamel Kitchen \\
\hline
\end{tabular}

Sumber : ICMD, data diolah 
Tabel 2: Nama CEO Pria, Perusahaan dan jenis usaha

\begin{tabular}{lll}
\hline Nama CEO & Nama Perusahaan & Kelompok usaha \\
\hline Maurits Daniel Rudolf L & Unilever Indonesia & Consumer goods \\
Andy Sunjaya H & Leo Investama & Others Internet Service \\
Ali Sugiharto Wibisono & Kedawung Setia & Industrial Enamel Kitchen \\
\hline
\end{tabular}

Sumber: ICMD, data diolah

Tabel 3: Rasio leverage dan ROI Perusahaan terpilih periode 2001-2008

\begin{tabular}{|c|c|c|c|c|}
\hline \multirow{4}{*}{ Tahun } & \multicolumn{4}{|c|}{ Perusahaan dengan rasio leverage dan ROI } \\
\hline & \multicolumn{4}{|c|}{ CONSUMER GOODS } \\
\hline & \multicolumn{2}{|c|}{ CEO Wanita (PT Mustika Ratu) } & \multicolumn{2}{|c|}{ CEO Pria (PT. Unilever) } \\
\hline & Rasio Leverage & ROI & Rasio Leverage & ROI \\
\hline 2001 & 0.16 & 12.33 & 0.36 & 33.08 \\
\hline 2002 & 0.18 & 7.01 & 0.34 & 31.64 \\
\hline 2003 & 0.16 & 3.95 & 0.38 & 37.96 \\
\hline 2004 & 0.16 & 4.47 & 0.37 & 40.08 \\
\hline 2005 & 0.12 & 2.93 & 0.43 & 37.48 \\
\hline 2006 & 0.09 & 3.12 & 0.49 & 37.22 \\
\hline 2007 & 0.12 & 3.52 & 0.49 & 36.79 \\
\hline \multirow[t]{4}{*}{2008} & 0.14 & 6.28 & 0.52 & 37.01 \\
\hline & \multicolumn{4}{|c|}{ Internet Service } \\
\hline & \multicolumn{2}{|c|}{ CEO Wanita (PT. Dyviacom) } & \multicolumn{2}{|c|}{ CEO Pria (PT. Leo Investama) } \\
\hline & Rasio Leverage & ROI & Rasio Leverage & ROI \\
\hline 2001 & .18 & -22.13 & 0.33 & 3.52 \\
\hline 2002 & 0.21 & -10.92 & 0.38 & -28.03 \\
\hline 2003 & 0.26 & -8.72 & 0.91 & -2.57 \\
\hline 2004 & 0.33 & -7.39 & 0.50 & -5.90 \\
\hline 2005 & 0.33 & -7.11 & 0.73 & -16.64 \\
\hline 2006 & 0.36 & -.69 & 0.78 & 0.38 \\
\hline 2007 & 0.36 & 5.64 & 0.90 & -8.05 \\
\hline \multirow[t]{4}{*}{2008} & 0.43 & 0.37 & 1.13 & -23.94 \\
\hline & \multicolumn{4}{|c|}{ Enamel Kitchen } \\
\hline & \multicolumn{2}{|c|}{ CEO Wanita (PT. Kedaung Indah Can } & \multicolumn{2}{|c|}{$\begin{array}{l}\text { CEO Pria. PT Kedawung Setia } \\
\text { Industrial }\end{array}$} \\
\hline & Rasio Leverage & ROI & Rasio Leverage & ROI \\
\hline 2001 & 0.38 & 4.01 & 0.69 & -4.31 \\
\hline 2002 & 0.37 & -1.55 & 0.70 & -0.79 \\
\hline 2003 & 0.37 & -7.36 & 0.72 & -5.15 \\
\hline 2004 & 0.46 & -10.69 & 0.78 & -5.99 \\
\hline 2005 & 0.52 & -6.30 & 0.79 & -1.92 \\
\hline 2006 & 0.22 & -10.57 & 0.65 & 1.67 \\
\hline 2007 & 0.22 & 19.61 & 0.59 & 2.68 \\
\hline 2008 & 0.24 & 3.55 & 0.53 & 1.18 \\
\hline
\end{tabular}

(sumber: ICMD terbitan Bursa Efek Jakarta)

\section{HASIL PENELITIAN DAN} PEMBAHASAN

Menggunakan data yang sudah diolah dalam SPSS, maka analisis data akan membahas tentang perbedaan financial risk yang tercermin dalam penggunaan leverage dalam perusahaan antara perusahaan dengan $\mathrm{CEO}$ wanita dan perusahaan dengan CEO Pria. Setelah itu selanjutnya akan dianalisis tentang perbedaan kinerja (yang tercermin dalam return on 
investment perusahaan) antara perusahaan dengan CEO wanita dan perusahaan dengan CEO Pria.

\section{Perbedaan dalam Financial Risk antara CEO Wanita dan CEO Pria}

Dari pemilihan data diperoleh tiga (3) jenis industry yang memiliki perusahaan dengan CEO wanita selama periode penelitian (20012008). Ketiga jenis indutri tersebut adalah: consumer goods, internet service dan enamel kitchen. Maka berikut ini akan dianalisis hasil output dari pengolahan data dengan menggunakan program statistik SPSS versi 15, untuk masing-masing industri tersebut.

\section{Consumer Goods}

Untuk jenis industri consumer goods hasil t-tes menggunakan SPSS diperoleh output sebagaimana tampak pada Tabel 4. Dari hasil pengujian tersebut maka bisa dikatakan bahwa untuk industri consumer goods ini, ada perbedaan pengguanaan leverage antara perusahaan yang CEO-nya wanita dan perusahaan yang CEO-nya pria. Perusahaan dengan CEO Pria memiliki rata-rata leverage yang lebih besar, yaitu 0.4225 bila dibandingkan dengan perusahaan dengan $\mathrm{CEO}$ wanita yang rata-rata leveragenya adalah 0.1412. Tapi apakah perbedaan ini signifikan secara statistik maka haruslah dilihat hasil nilai T-Testnya. Melihat hasil F-tes sebesar 10.942 dan memiliki probabilitas 0.005 yang berarti lebih kecil dibandingkan 0.05, maka Equal Variances not assumed harus digunakan untuk melihat hasil T Test-nya. Dari Tabel 4 terlihat bahwa angka uji t menunjukkan angka -10.518 dengan probablitas signifikansi .000 (two tailed).
Dari hasil tersebut bisa diartikan bahwa pada industri consumer goods ada perbedaan yang signifikan atas penggunaan rata-rata leverage antara perusahaan dengan CEO pria dan perusahaan dengan CEO wanita. Perusahaan dengan CEO pria memiliki leverage yang lebih besar dibandingkan dengan perusahaan yang CEO-nya adalah wanita.

\section{Internet Service}

Untuk jenis industri internet services, hasil t-tes menggunakan SPSS diperoleh output sebagaimana tampak pada tabel 5. Dari hasil pengujian $\mathrm{t}$ test yang nampak pada Tabel 5, bisa dikatakan bahwa untuk industri internet services ini, ada perbedaan dalam rata-rata penggunaan leverage antara perusahaan denganCEO wanita dan perusahaan dengan CEO pria. Perusahaan dengan CEO Pria memiliki rata-rata leverage yang lebih besar dibandingkan wanita, yaitu 0.7075 untuk CEO pria dan 0.3075 untuk CEO wanita. Tapi apakah perbedaan ini signifikan secara statistik maka harus dilihat hasil nilai $\mathrm{T}$ Testnya. Equal Variances not assumed digunakan karena dari hasil F-tes menunjukkan angka sebesar 9.479 dan memiliki probabilitas 0.008 yang berarti lebih kecil dibandingkan 0.05. Setelah itu baru dilihat hasil t test-nya. Dari Tabel 5 terlihat bahwa angka uji t menunjukkan angka -3.849 dengan probablitas signifikansi .005 (two tailed). Hal ini berarti nilai $\mathrm{t}$ lebih kecil dibandingkan dengan 0.05 , maka ini berarti untuk jenis industri internet service penggunaan rata-rata leverage secara signifikan berbeda antara perusahaan dengan CEO pria dan perusahaan dengan CEO wanita. CEO pria menggunakan leverage yang lebih besar untuk perusahaan yang mereka kelola bila dibandingkan dengan CEO wanita dalam menjalankan perusahaan yang mereka pimpin.

Tabel 4. Hasil uji beda T-Test antara CEO wanita(PT. Mustika Ratu) dan CEO pria (PT. Unilever)atas financial risk untuk kelompok Consumer Goods

\begin{tabular}{llllrlrr}
\hline & \multirow{2}{*}{ Jender } & $\mathrm{N}$ & Mean & St Deviation & \multicolumn{3}{c}{$\mathrm{T}$ test for equality Means } \\
\cline { 6 - 8 } & & & & $\mathrm{t}$ & $\mathrm{df}$ & Sig (2 tailed) \\
\hline Rasio & Female & 8 & 0.1412 & 0.02949 & -10.518 & 9.432 & .000 \\
Leverage & Male & 8 & 0.4225 & 0.6954 & & & \\
\hline
\end{tabular}

Sumber: hasil pengolahan data dengan SPSS 
Tabel 5: Hasil uji beda T-Test antara CEO wanita (PT. Dyviacom) dan CEO pria (PT. Leo Investama ) atas financial risk untuk kelompok Internet Service

\begin{tabular}{llllrlrr}
\hline & \multirow{2}{*}{ Jender } & \multirow{2}{*}{$\mathrm{N}$} & \multirow{2}{*}{ Mean } & \multirow{2}{*}{ St Deviation } & \multicolumn{3}{c}{ T testfor equality Means } \\
\cline { 6 - 8 } & & & & $\mathrm{t}$ & $\mathrm{df}$ & Sig (2 tailed) \\
\hline Rasio & Female & 8 & 0.3075 & 0.08413 & -3.849 & 8.240 & .005 \\
Leverage & Male & 8 & 0.7075 & 28162 & & & \\
\hline
\end{tabular}

Sumber: hasil pengolahan data dengan SPSS

\section{Enamel Kitchen}

Tabel 6: Hasil uji beda T-Test antara CEO wanita (PT. Kedaung Indah Can) dan CEO pria (PT. Kedaung Setia Industrial) atas financial risk untuk kelompok Enamel Kitchen

\begin{tabular}{llllrrrr}
\hline & \multirow{2}{*}{ Jender } & $\mathrm{N}$ & \multirow{2}{*}{ Mean } & \multirow{2}{*}{ St Deviation } & \multicolumn{3}{c}{$\mathrm{T}$ test for equality Means } \\
\hline Rasio & Female & 8 & 0.3475 & 0.11247 & -6.576 & 14 & Sig (2 tailed) \\
Leverage & Male & 8 & 0.6813 & 0.8919 & & & .000 \\
\hline
\end{tabular}

Sumber: hasil pengolahan data dengan SPSS

Dari hasil pengujian $t$ test pada Tabel 6, bisa dikatakan bahwa untuk industri enamel kitchen, ada perbedaan rata-rata penggunaan leverage antara perusahaan dengan CEO wanita dan perusahaan dengan CEO pria. Perusahaan dengan CEO Pria memiliki rata-rata leverage yang lebih besar, yaitu 0.6813 dibandingkan dengan perusahaan dengan CEO wanita yang hanya sebesar memiliki rata-rata leverage sebesar 0.3475. Tapi apakah perbedaan ini signifikan secara statistik maka harus dilihat hasil nilai T-Testnya. Equal Variances assumed digunakan karena dari hasil F-tes sebesar 9.479 dan memiliki probabilitas 0.426 yang berarti lebih besar dibandingkan 0.05. Dari Tabel 6 terlihat bahwa angka uji t menunjukkan angka 6.576 dengan probablitas signifikansi .000 (two tailed) yang berarti lebih kecil dari 0.05, maka ini berarti bahwa ada perbedaan penggunaan rata-rata leverage secara signifikan antara perusahaan dengan CEO pria dan perusahaan dengan CEO wanita. CEO pria menggunakan leverage yang lebih besar dibandingkan dengan CEO wanita ketika mereka menjalankan perusahaan mereka.

Jadi, dari hasil uji beda t-test utuk ketiga industri (yaitu: consumer goods, internet service, dan enamel kitchen) menunjukkan bahwa ada perbedaan yang signifikan antara perusahaan dengan CEO wanita dan perusahaan dengan CEO pria dalam penggunaan rata-rata leverage mereka. Untuk semua industri yang terpilih, dapat dikatakan bahwa perusahaan dengan CEO pria memiliki rata-rata leverage yang lebih besar bila dibandingkan dengan perusahaan yang ber-CEO wanita. Hal ini sesuai dengan teori yang mengatakan bahwa pria adalah risk taker. Mereka memiliki kecenderungan lebih berani dalam pengambilan risiko keuangan mereka, yaitu dengan lebih berani memiliki hutang yang lebih besar dengan harapan bisa memperbesar return yang bisa mereka hasilkan. Hutang yang besar akan membuat perusahaan memiliki beban tetap yang harus mereka bayar, sehingga akan memperbesar risiko financial mereka. Namun, High risk high return, sehingga risiko yang besar akan memberikan return yang besar.

Sedangkan wanita menurut berbagai penelitian adalah risk averse yang berarti memiliki kecenderungan untuk menolak risiko, sehingga mereka cenderung tidak memiliki keberanian untuk memiliki hutang yang besar dalam mengelola perusahaan yang mereka pimpin. Karena meningkatnya hutang akan berarti meningkatkan risiko keuangan mereka, maka kaum wanita akan lebih berhati-hati dalam menggunakan hutang sebagai sumber modal mereka.

\section{Perbedaan Kinerja antara perusahaan dengan CEO wanita dan CEQria}

Analisis selanjutnya adalah akan melihat apakah ada perbedaan kinerja antara perusahaan dengan $\mathrm{CEO}$ pria dan perusahaan dengan CEO wanita. Hasil pengolahan data dengan SPSS atas T-test, untuk menguji perbedaan kinerja antara CEO pria dan CEO wanita atas perusahaan yang mereka pimpin, untuk ketiga industri yang terpilih akan diuraikan dalam pembahasan berikut. 


\section{Consumer Goods}

Tabel 7: Hasil uji beda T-Test antara CEO wanita (PT. Mustika Ratu) dan CEO pria (PT. Unilever) atas kinerja untuk kelompok Consumer Goods

\begin{tabular}{lllrrrrr}
\hline & \multirow{2}{*}{ Jender } & \multirow{2}{*}{$\mathrm{N}$} & \multicolumn{1}{c}{ Mean } & \multirow{2}{*}{ St Deviation } & \multicolumn{3}{c}{ T test for equality Means } \\
\cline { 6 - 8 } & & & & \multicolumn{1}{c}{$\mathrm{t}$} & $\mathrm{df}$ & Sig (2 tailed) \\
\hline ROI & Female & 8 & 5.4513 & 3.14351 & -21.043 & 14 & .000 \\
& Male & 8 & 36.4075 & 2.72603 & & & \\
\hline
\end{tabular}

Sumber: hasil pengolahan data dengan SPSS

Dari hasil pengujian $\mathrm{t}$ test yang nampak pada Tabel 7, bisa dikatakan bahwa untuk industry consumer goods, ada perbedaan kinerja antara perusahaan dengan CEO wanita dan perusahaan dengan CEO pria. Perusahaan dengan CEO Pria memiliki rata-rata ROI yang lebih besar, yaitu 36.4075 dibandingan dengan rata-rata ROI yang dimiliki perusahaan dengan CEO wanita yaitu sebesar 5.4513. Tapi apakah perbedaan ini signifikan secara statistik maka harus dilihat hasil nilai T-Testnya. Dalam pengujian ini Equal Variances assumed digunakan karena dari hasil F-tes sebesar 0.106 memiliki probabilitas 0.750 yang berarti lebih besar dibandingkan 0.05. Dari Tabel 6 terlihat bahwa angka uji t menunjukkan angka -21.043 dengan probablitas signifikansi .000 (two tailed) yang berarti lebih kecil dari 0.05 , maka ini berarti bahwa ada perbedaan kinerja yang signifikan antara perusahaan dengan CEO pria dan perusahaan dengan CEO yang tercermin dalam rata-rata ROI yang dimiliki masingmasing perusahaan tersebut. Arrtinya perusahaan dengan CEO pria memiliki kinerja yang lebih baik (tercermin dari rata-rata nilai ROI yang lebih besar) dibandingkan dengan perusahaan dengan CEO wanita.

\section{Internet Service}

Dari hasil pengujian $\mathrm{t}$ test yang nampak pada Tabel 8, bisa dikatakan bahwa untuk industri internet service ada perbedaan kinerja antara perusahaan dengan CEO wanita dan perusahaan dengan CEO pria. Perusahaan dengan CEO Pria memiliki rata-rata ROI yang lebih besar secara negative yaitu -10.1538 (yang berarti perusahaan ada dalam kondisi rugi), dibandingkan dengan perusahaan dengan CEO wanita, yaitu sebesar -6.3687. Tapi apakah perbedaan ini signifikan secara statistik maka harus dilihat hasil nilai T-Testnya. Equal Variances assumed digunakan karena dari hasil Ftes sebesar 1.840 memiliki probabilitas 0.221 yang berarti angka ini lebih besar dibandingkan 0.05. Dari Tabel 8 terlihat bahwa angka uji $\mathrm{t}$ menunjukkan angka 0.750 dengan probablitas signifikansi 0.466 (two tailed) yang berarti lebih besar dari 0.05 , maka ini berarti bahwa tidak ada perbedaan kinerja antara perusahaan dengan CEO pria dan perusahaan dengan CEO, meskipun CEO pria memiliki ROI yang lebih besar dibandingkan dengan ROI yang dimiliki perusahaan dengan CEO wanita.

\section{Enamel Kitchen}

Hasil ouput SPSS untuk T-test atas indiustri Enamel Kitchen, hasilnya nampak pada Tabel 9.

Tabel 8: Hasil uji beda T-Test antara CEO wanita (PT. Dyviacom) dan CEO pria (PT. Leo Investama ) atas kinerja (ROI) untuk kelompok Internet Service

\begin{tabular}{lllrrrrr}
\hline & \multirow{2}{*}{ Jender } & \multirow{2}{*}{$\mathrm{N}$} & \multicolumn{2}{c}{ Mean } & \multirow{2}{*}{ St Deviation } & \multicolumn{3}{c}{$\mathrm{T}$ test for equality Means } \\
\cline { 6 - 8 } & & & & & $\mathrm{t}$ & $\mathrm{df}$ & Sig (2 tailed) \\
\hline ROI & Female & 8 & -6.3687 & 8.43564 & 0.750 & 14 & .466 \\
& Male & 8 & -10.1538 & 11.52424 & & & \\
\hline
\end{tabular}

Sumber: hasil pengolahan data dengan SPSS

Tabel 9: Hasil uji beda T-Test antara CEO wanita (PT. Kedaung Indah Can) dan CEO pria (PT. Kedaung Setia Industrial) atas Kinerja untuk kelompok Enamel Kitchen

\begin{tabular}{llrrrrrr}
\hline & \multirow{2}{*}{ Jender } & \multirow{2}{*}{$\mathrm{N}$} & \multirow{2}{*}{ Mean } & \multirow{2}{*}{ St Deviation } & \multicolumn{3}{c}{ T test for equality Means } \\
\cline { 6 - 8 } & & & & $\mathrm{t}$ & $\mathrm{df}$ & Sig (2 tailed) \\
\hline ROI & Female & 8 & -1.1625 & 10.17480 & 0.110 & 8.466 & .915 \\
& Male & 8 & -1.5788 & 3.31044 & & & \\
\hline
\end{tabular}

Sumber: hasil pengolahan data dengan SPSS 
Dari hasil pengujian $\mathrm{t}$ test yang nampak pada Tabel 9, bisa dikatakan bahwa untuk industri enamel kitchen ada perbedaan kinerja antara perusahaan dengan CEO wanita dan perusahaan dengan CEO pria. Perusahaan dengan CEO Pria memiliki rata-rata ROI yang lebih besar secara negative yaitu -1.5788 (yang berarti perusahaan dalam kondisi rugi) dibandingkan dengan rata-rata ROI perusahaan dengan CEO wanita yaitu sebesar -1.1625 . Tapi apakah perbedaan ini signifikan secara statistik maka harus dilihat hasil nilai T-Testnya. Equal Variances not assumed digunakan karena dari hasil F-tes sebesar 0.4975 memiliki probabilitas 0.043 yang berarti lebih kecil dibandingkan 0.05. Dari Tabel 8 terlihat bahwa angka uji t menunjukkan angka 0.110 dengan probablitas signifikansi 0.915 (two tailed) yang berarti lebih besar dari 0.05, maka ini berarti bahwa tidak ada perbedaan kinerja antara perusahaan dengan CEO pria dan perusahaan dengan CEO wanita yang dilihat dari ROI atas perusahaan yang mereka pimpin, meskipun rata-rata ROI perusahaan dengan CEO pria lebih besar dibandingkan dengan perusahaan dengan CEO wanita.

Jadi, dari hasil analisis uji beda kinerja antara perusahaan dengan CEO Pria dan CEO Wanita menunjukkan hasil yang berbeda untuk ketiga jenis industri terpilih. Untuk industri Consumer Goods, menunjukkan hasil bahwa ada perbedaan kinerja antara antara perusahaan dengan CEO pria dan perusahaan dengan CEO wanita. Namun hal ini tidak terjadi pada kedua industri yang lain yaitu industri internet service dan enamel kitchen.

\section{Analisis Perbedaan leverage dan kinerja antara CEO wanita dan CEO Pria}

Hasil penelitian pada ketiga jenis industry yang menjadi sampel penelitian ini (consumer goods, internet services dan enamel kitchen), menunjukkan bahwa ada perbedaan yang signifikan atas penggunaan leverage antara perusahaan yang CEO-nya pria dan perusahaan yang CEO -nya wanita. Perusahaan dengan CEO pria memiliki leverage yang lebih besar di bandingkan dengan perusahaan dengan CEO wanita. Ini berarti bahwa para CEO pria lebih banyak menggunakan hutang dalam menjalankan perusahaannya, sedangkan untuk perusahaan yang
CEO nya wanita memiliki hutang yang lebih sedikit.

Secara teoritis penambahan hutang dalam struktur modal perusahaan dilakukan dengan harapan akan memperbesar return (laba) perusahaan. Financial leverage merefleksikan jumlah hutang yang digunakan perusahaan. Namun, penambahan hutang juga akan memperbesar financial risk perusahaan karena penggunaan hutang akan menimbulkan beban tetap. Karena pria adalah risk taking maka itu tercermin dalam keberanian mereka dalam memanfaatkan hutang sebagai sumber modal mereka dalam rangka memperbesar skala perusahaan. Berbeda dengan CEO wanita yang lebih memilih menggunakan hutang yang relatif lebih kecil. Penemuan ini semakin menguatkan penelitian empiris yang sudah ada bahwa wanita adalah risk everse. Females are often found to be, on average, less willing to take risk (Eckel and Grossman, 2008; Bernasek and Jianakoplos, 1998; Sunden and Surette, 1998; Barber and Odean, 2001). Henning and Jardin (1977) Women view risk as loss, danger ruin and hurt and they do not see risk as affecting their future. In short, women tend to avoid risky actions and decicions compared with men. Zahid et al, (2006), As corporate executive, however, women are less risk averse than their male counterparts.

Meskipun rata-rata leverage perusahaan yang digunakan oleh CEO wanita dalam kedua industri ini lebih kecil dibandingkan CEO pria, namun bukan berarti kemampuan CEO wanita dalam menghasilkan return lebih kecil dibandingkan pria. Dari hasil pengujian $\mathrm{T}$ Test untuk menguji perbedaan antara CEO pria dan wanita dalam ROI mereka atas perusahaan yang mereka pimpin pada ketiga industri yang terpilih sebagai obyek penelitiaan, menunjukkan adanya perbedaan hasil analisis.

Untuk jenis industri consumer goods, hasil analisis data menunjukkan bahwa ada perbedaan kinerja yang signifikan antara perusahaan dengan CEO pria dan perusahaan dengan CEO wanita yang diukur dari ROI yang dimiliki masing-masing perusahaan. Perusahaan dengan CEO pria memiliki ROI yang lebih besar dibandingkan dengan perusahaan yang CEO-nya wanita. Namun untuk industri internet service dan enamel kitchen hasil analisis data menunjukkan bahwa tidak ada perbedaan yang signifikan atas kinerja antara 
perusahaan yang CEO-nya pria dan perusahaan yang CEO-nya wanita.

Pada industry consumer goods, CEO pria memiliki rata-rata leverage dan kinerja yang lebih besar dibandingkan dengan CEO wanita, karena memang secara tradisional pria lebih risk taker dibandingkan dengan wanita yang lebih risk averse. Itu mengapa pada industry consumer goods ini, hasil penelitian menunjukkan ada perbedaan baik dalam ratarata penggunaan leverage maupun kinerja mereka. High risk high return, risiko yang besar menjanjikan return yang besar pula. Karena pria lebih berani mengambil risiko (dengan memiliki hutang yang lebih besar dibandingkan wanita), maka mereka juga akan bisa mendapatkan return yang besar atas keberanian mereka, tercermin dengan kinerja ROI mereka yang lebih besar dibandingkan dengan perusahaan yang CEO-nya wanita.

Menurut penulis perbedaan hasil ini bisa dianalisis dengan penjelasan berikut. PT. Mustika Ratu (pada jenis industry consumer goods) adalah perusahaan yang memproduksi herbal dan kosmetik tradisional yang sangat kental dengan budaya jawa, karena CEO-nya yang seorang wanita, yaitu BRA. Mooryati Soedibyo adalah keturunan ningrat jawa yang memilki budaya jawa yang sangat kental dengan tradisi. Sehingga sangat masuk akal jika budaya jawa itu tercermin juga dalam perilaku pengambilan keputusan mereka. Dalam budaya jawa, wanita yang sering diartikan sebagaiwani di tata (harus berani di atur) memiliki kewajiban sebagai pendamping suami sehingga secara kultural wanita adalah bukan pengambil keputusan. Karena budaya itulah maka wanitawanita yang masih berada dalam lingkungan jawa yang kental, kemungkinan juga mereka memliki kecenderungan risk averse, karena secara cultural kedudukan mereka selalu ada dibelakang pria, yang berarti tidak punya kewajiban sebagai pengambil keputusan dan itu mengakibatkan mereka tidak mempunyai keberanian yang kuat untuk mengambil risiko yang lebih besar. Meskipun apabila mereka telah menjadi seorang pemimpin perusahaan besar, maka mereka secara psikologis pastilah punya kecenderungan untuk sangat berhati-hati dalam mengambil keputusan ketika mereka menjalankan perusahaannya. Itu mengapa dalam penelitian ini, untuk jenis industry consumer goods baik untuk leverage maupun kinerja, ada perbedaan yang signifikan antara CEO pria (yang diwakili oleh PT. Unilever) dan CEO wanita (yang diwakili oleh PT. Mustika Ratu). Sesuai dengan hasil studi Teoh and Chong (2007) yang menyatakan bahwa dari perspektif lingkungan, pengaruh keluarga, khususnya pengaruh orang tua memainkan peran yang utama dalam penetapan desirability dan credibility dari enterprenneur tersebut. Stein dan Bailey (1973) menyatakan bahwa: Female labour force participation also seems to be related to the attitude of the family towards women. Aminah (2008) dalam studinya tentang wanita karir yang sukses di Malaysia, menunjukkan bahwa perubahan sikap orang tua dan suami yang lebih menuju ke arah positif yang ditunjukkan dengan pencapaian pendidikan yang lebih tinggi yang dicapai wanita dapat mempengaruhi partisipasi wanita dalam angkatan kerja dengan menetapkan bisnis mereka sendiri.

Namun adanya perbedaan kinerja antara perusahaan dengan CEO pria dan perusahaan dengan CEO wanita ini, ternyata tidak terjadi pada dua industri yang lain, yaitu internet service dan enamel kitchen. Menurut penulis mengapa untuk kedua jenis indutri ini tidak ada perbedaan dalam kinerja antara perusahaan yang CEO-nya pria dan perusahaan yang CEO-nya wanita adalah karena untuk kedua industri ini, ada kemungkinan CEO mereka adalah wanita-wanita yang bukan berlatar belakang budaya jawa yang kental seperti pada PT. Mustika Ratu pada industri consumer goods, dimana CEO-nya berlatar belakang ningrat jawa yang kental. Selain itu kemungkinan mereka juga adalah wanita dengan pendidikan tinggi yang terbiasa dengan gaya yang lebih modern dimana pada umumnya mereka memiliki pandangan bahwa wanita memilki kesamaan derajad dengan pria. Sehingga itu semua juga akan tercermin dalam kemampuan mereka dalam mengelola perusahaan.

Pandangan bahwa wanita memilki derajad dan kemampuan yang sama dengan pria, akan membuat mereka selalu berusaha menunjukkan, tentu saja dengan kerja keras, bahwa mereka memilki prestasi yang tidak berbeda dengan pria, sehingga kinerja yang mereka capai dalam memimpin sebuah perusahaan juga tidak akan jauh berbeda denga pria. Secara alamiah wanita yang menjadi pemimpin pasti akan dengan sekuat tenaga 
menunjukkan bahwa dirinya sama hebatnya dengan kaum pria. Sesuai dengan hipotesa dari Strelcova (2004) dalam peneltiannya: Does Jender Matter? A Comparative Study of Performance of American CEOs menyatakan bahwa wanita yang pada akhirnya mencapai posisi CEO, pasti memilki superior skills relative dibandingkan dengan pesaingnya yaitu kaum pria. Jadi masuk akal jika kinerja mereka tidak akan berbeda dengan kaum pria, atau bahkan bisa melebihi mereka jika didukung oleh faktor-faktor lain. Hal itu terlihat dalam penelitian ini, dimana tidak ada perbedaan kinerja antara perusahaan yang CEO-nya pria dan perusahaan yang CEO-nya wanita yang diukur dari Return On investment (ROI) yang dimiliki perusahaan setiap tahun.

Niessen and Ruenzi (2006) find no evidence that risk-related behavioural differences female and male fund managers are reflected in fund performance. Sejalan dengan penelitian Brush (1990), individual motivations and goals such as profitability, revenues and sales growth have been found to be related to performance in woman-owned business, albeit their tendendy to perform less well than their male counterparts. Di Malaysia, penelitian Nordin (2005) menunjukkan bahwa motif psikologikal seperti kepuasan pribadi dan pencarian atas independensi dan factor lingkungan yang mendukung mempengaruhi wanita dalam menjalankan bisnisnya. Storey (1994) dan Glancey et al (1998) menemukan bahwa wanita terdorong untuk menempatkan perusahaannya lebih profiTabel dan mendapatkan profit margin yang lebih besar.

\section{KESIMPULAN DAN IMPLIKASI}

Dari hasil analisis data di halaman terdahulu, maka dapat diambil kesimpulan bahwa ada perbedaan yang signifikan dalam penggunaan leverage antara perusahaan dengan CEO pria dan perusahaan dengan CEO wanita. Perusahaan dengan CEO pria menggunakan leverage lebih besar dibandingkan perusahaan dengan CEO wanita. Hal ini terjadi pada ketiga jenis industri yang menjadi obyek bagi penelitian ini. Ini membuktikan bahwa wanita memang risk averse dibandingkan pria yang lebih risk taker. Meningkatnya hutang dalam struktur modal perusahaan akan mengakibatkan meningkatnya beban tetap bagi perusahaan tersebut, dan itu berarti akan meningktkan juga risiko financial perusahaan. Dari penelitian ini Nampak bahwa wanita lebih suka menggunakan hutang yang lebih kecil dibandingkan pria atau bahkan menghindarinya dan lebih memilih mengunakan jenis modal yang lain.

Hasil penelitian ini berbeda dengan Penelitian terdahulu untuk CEO di US, yang menunjukkan hasil bahwa tidak ada perbedaan leverage antara CEO pria dan CEO wanita (Jelena, 2004). Namun searah dengan beberapa penetian lain seperti Bajttlsmith Dn VanDerhei (1996), dan Hinz, McCarthy and Turner (1996) menemukan bahwa wanita menginvestasikan uang pension mereka lebih konservatif dibandingkan pria. Jaiankoplos dan Bernasek (1996) pada penelitiannya menunjkkan bahwa wanita single relatif lebih risk averse dibanding pria atau pasangan yang menikah. Penelitian ini juga membandingkan toleransi atas risiko antara kelompok yang berbeda dan hasilnya adalah wanita menerima diri mereka sendiri sebagi risk averse.

Sedangkan dalam kinerja, ternyata menunjukkan hasil yang berbeda di ketiga jenis industry yang di teliti. Pada industry consumer goods, hasil pengujian menunjukkan bahwa ada perbedaan kinerja antara perusahaan dengan CEO pria dan perusahaan dengan CEO wanita, yang diukur dari Return On Investment perusahaan tiap tahun. Menurut analisis penulis ini lebih disebabkan oleh masih kentalnya budaya jawa yang dimiliki oleh CEO wanita pada industry consumer goods.

Namun hal ini tidak terjadi pada industry internet service dan enamel kitchen. Pada kedua industry ini, yaitu internet service dan enamel kitchen hasil penelitin menunjukkan bahwa tidak ada perbedaan kinerja yang signifikan antara perusahaan dengan CEO pria dan perusahaan dengan CEO wanita. Hasil ini sejalan dengan penelitian dari Niessen and Ruenzi (2006) menemukan bukti bahwa tidak ada bukti yang menunjukkan perbedaan antara wanita dan pria dalam perilaku fund manager atas kinerja mereka.

Menurut analisis penulis, hal ini dikarenakan CEO wanita pada kedua industri ini kemungkinan memiliki latar belakang pendidikan yang lebih modern yang memiliki pandangan bahwa wanita memilki kemampuan yang sama denga pria, sehingga mereka selalu akan menunjukkan kemampuan yang sama 
dengan kaum pria. Bahkan secara alami mereka akan berusaha keras untuk melakukan itu di tengah persaingan yang didominasi kaum pria.

Strelcova, 2004), Berdasarkan penelitian terdahulu, wanita didiskriminasi ketika saatnya promosi jabatan untuk posisi manajerial yang lebih tinggi, sehingga wanita yang bisa mencapai posisi CEO pasti memiliki superior skills yang relatif lebih tinggi dibandingkan pesaingnya, yaitu pria. Oleh karena itu mereka pasti akan menghasilkan kinerja yang superior. Smith (2005) menyatakan bahwa hasil penelitiannya menunjukkan hasil yang positif antara kinerja manajer wanita dengan pendidikan tinggi (university degree). Sudarsanam dan Huang (2007) ...even more, women try to out macho men and assume even more risk than men.

Hasil penelitian ini semakin memperkuat fakta bahwa hampir di beberapa Negara yang pernah melakukan penelitian tentang topuk ini, wanita adalah tetap risk averse, yang berarti mereka lebih suka menghindari risiko. Menurut Schubert, R. (2006), Hal ini mengindikasikan bahwa wanita lebih memiliki ketakutan atas kerugian dan lebih pesimistik dibandingkan pria. Gupta, et al, (2009), menuliskan bahwa Term the "glass cliff" in recognition oh the high - risk nature of the opportunity, research found that in times of positif performances, organizations "think opportunity, think men." Yet in times of high risk, organizations, "think crisis, think women" and often put women into top leadership, relying on their relational skills to turn organization around. Artinya wanita masih dipandang sebagai individu yang memiliki perilaku lebih berhati-hati dibandingkan pria yang lebih berani mengambil risiko (peluang). Implikasinya adalah agar wanita bisa mempertinggi potensi karir merekadalam perusahaan dan bisa menghasilkan kinerja yang sama dengan pria, maka mereka harus menggunakan bahasa risiko (memperhitungkan antara cost and benefit), mampu mempromosikan kemampuan mereka secara nyata, dan harus mau bekerja sama dengan orang lain yang lebih risk taker dalam organisasi. Bagaimanapun high risk high return tetap berlaku, sehingga bila wanita ingin memiliki kinerja yang sama dengan pria, maka mereka harus lebih berani mengambil risiko.

Penelitian ini juga masih sangat sederhana, karena hanya menggunakan data sekunder yang diterbitkan oleh pihak lain, yaitu
Bursa Efek Jakarta, sehingga sampel yang diperoleh sangat terbatas. Oleh karena itu bagi penelitian-penelitian selanjutnya, akan lebih baik jika menggunakan data primer yang dicari agar sesuai dengan kebutuhan penelitian, sehingga sampel bisa lebih banyak dan bisa didapatkan hasil penelitian yang lebih baik. Juga bisa dipertimbangkan untuk melakukan penelitian bagi perusahaan yang sama tetapi memilki CEO wanita dan CEO Pria pada periode kepemimpinan yang berbeda, sehingga bisa dilihat apakah dalam satu perusahaan dengan karakteristik yang sama, CEO wanita dan CEO Pria memiliki perbedaan dalan penggunaan hutang dan hasil kinerjanya. Selain itu bisa digunakan alat-alat statistik yang lain dan variabel-variabel penelitian yang lebih banyak, agar bisa memperkuat kesimpulan dari hasil analisis.

\section{DAFTAR PUSTAKA}

Adler, RD. 2001. "Women in the Executive Suite Correlate to High Profits, Working Paper, Malibu CA, Pepperdinr University, available at: http://www.equalpay.nu/en_fakta.html

Aminah, A. 1998. Women in Malaysia. Retrieved April 20, 2006, from http://www.adb.org/Documents/Books/ Country_Briefing_Papers/Women_in_ Malaysia/w omen_malaysia.pdf

Atkinson, M. Stanley, B. Samantha, Baird, and MB. Frye. 2003. Do female mutual fund managers manage differently?, Journal of Financial Research. 26. 1-18.

Beckmann, Daniela, and L. Menkhoff. 2008. Will women be women? Analyzing the jender difference among financial experts. KYKLOS. 61. 364-384.

Bell, LA. 2005. Women-Led Firms and the Jender Gap in Top Executive Jobs, IZA discussion paper 1689, IZA, Bonn

Byrnes, JP., DC. Miller, and WD. Schafer. 999. Jender differences in risk-taking: A meta-analysis, Psychological Bulletin.

Carter, DA., BJ Simkins and WG. Simpson. 2003. Corporate Governance, Board Diversity, and Firm Value, The Financial Review. 38. 33-53. 
Catalyst. 2004. The Bottom Line: Connecting Corporate Performance and Jender Diversity, New York, NY, available at: http://www.catalyst.org/

Du Rietz, A and M. Henrekson. 2000. Testing the Female Underperformance Hypothesis, Small Business Economics. 14(1). 1-10.

Dwyer, Peggy D., James H. Gilkeson, and JA. List. 2002. Jender differences in revealed risk taking: evidence from mutual fund investors, Economic Letters. 76. 151-158.

Dwyer, S., OC. Richard dan K. Chadwick. 2003. Jender diversity in Management and Firm Performance: The Influence of Growth Orientation and Organizational Culture, Journal of Business research. 56 (12). 1009-1019.

Eckel, C. Chaterine, Grossman, and J. Philip. 2008. Men, Women and Risk Aversion, working paper, Department of Economic, Virginia Tech.

Francoeur, Claude, R. Labelle, and B. SinclairDesgagné. 2008. Jender diversity in corporate governance and top management, Journal of Business Ethics. 81. 83-95.

Ghozali. 2006. Statistik Non Parametrik: Teori \& Aplikasi dengan SPSS, Badan Penerbit UNDIP, Semarang, Indonesia.

Gupta, Vipin., Maxfield, Sylvia., Shapiro, Mary., dan Hass, Susan. 2009. Risky Business: Busting the Myth of Women as Risk Averse, Go Insight, Briefing Note Number 28.

Henning, $\mathrm{M}$ \& A. Jardim. 1977. The Managerial Woman, Anchor Press, Garden City, NY.

Jianakoplos, N., A. Bernashek. 1996. Are woman more riks averse? Colorado State University Working Paper.

Keown, J. Arthur, Martin, D. John, J. Petty William and Scott, Jr., David F. 2005. Financial Management: Principles and Applications, Prentice Hall.
Marinova, Joana; Plantenga, Janneke; Remery, Chantal. 2010. Performance: Evidence From Dutch and Danish Boardrooms, Netherlands.

Nieesen, A., dan Ruenzi, Stefan. 2006. Sex Matters: Jender and Mutual Funds, Working Paper, university of Cologne, Germany.

Rose. 2007. Does Female Board Representation Influence Firm Performance? The Danish Evidence, Corporate Governance. 15 (12). 404-413.

Schubert, R. 2006. Analyzing and Managing Risks-On the Importance of Jender differences in risk attitudes, Managerial Finance. 32 (9). 706-715.

Shrader, C.B., V.B. Blackburn and P. Iles. 1997. Women in Management and firm financial performance: an explorative study, Journal of Managerial Issues, fall 1997.9 (3). 355-372.

Smith, N., Smiyh, V., and Verner, M. 2005. Do Women in Top Management Affect Firm Performance? A Panel Study of 2,500 Danish Firms, International Journal of Productivity and Performance Management.

Strelcova, Jelena. 2004. Does Jender Matter? A comparative Study of Performance of American CEO's, The Leonard N. Stern School of Business Glucksman Institut for Research in Securities Markets.

Sudarsaman, Sudi; Huang, Jian. 2007. Jender Diversity in US Top Management: Impact on Risk Taking and Aquirer Performance, United Kingdom.

Wendy Ming-Yen, Teoh dan Shiong-Choy, Chong. 2007. Theorising a Framework of Factors Influencing Performance of Woman Enterpreneurs in Malaysia, Journal of Asia Enterpreneurship and Sustainability. 3 (2). September.

Zahid Lgbal, OH. Sewon, Young Baek. 2006. Are female Executives More RiskAverse than Male Executives? Atlantic Economic Journal. 34 (1). 